\title{
Antiproliferative Activity of Hamigerone and Radicinol Isolated from Bipolaris papendorfii
}

\author{
Periyasamy Giridharan, Shilpa A. Verekar, Akash R. Gohil, Prabhu Dutt Mishra, \\ Amit Khanna, and Sunil Kumar Deshmukh
}

Piramal Enterprises Ltd., 1 Nirlon Complex, Off Western Express Highway, Near NSE Complex, Goregaon (East), Mumbai 400 063, India

Correspondence should be addressed to Sunil Kumar Deshmukh; sunil.deshmukh@piramal.com

Received 27 May 2014; Accepted 16 July 2014; Published 12 August 2014

Academic Editor: Zeki Topcu

Copyright (C) 2014 Periyasamy Giridharan et al. This is an open access article distributed under the Creative Commons Attribution License, which permits unrestricted use, distribution, and reproduction in any medium, provided the original work is properly cited.

\begin{abstract}
Secondary metabolites from fungi organisms have extensive past and present use in the treatment of many diseases and serve as compounds of interest both in their natural form and as templates for synthetic modification. Through high throughput screening (HTS) and bioassay-guided isolation, we isolated two bioactive compounds hamigerone (1) and radicinol (2). These compounds were isolated from fungus Bipolaris papendorfii, isolated from the rice fields of Dera, Himachal Pradesh, India. The structures of the compounds were established on the basis of spectroscopic data, namely, NMR $\left({ }^{1} \mathrm{H},{ }^{13} \mathrm{C}\right.$, mass, and UV). Both compounds were found to be antiproliferative against different cancer cells. Furthermore we have also noted that both compounds showed increase in apoptosis by favorably modulating both tumor suppressor protein (p53) and antiapoptic protein (BCL-2), and in turn increase caspase- 3 expression in cancer cells. This is the first report of these compounds from fungus Bipolaris papendorfii and their anticancer activity.
\end{abstract}

\section{Introduction}

Microfungi are a rich source of chemical diversity [1-3], and its metabolites are used by the pharmaceutical industry either in the native form or as derivatives [4-6]. As only a small part of the Mycota is known and most fungi produce several unknown metabolites, fungi are still one of the most promising sources for new lead compounds. Hence fungi are the objective in numerous high throughput screening (HTS) programs targeting new pharmaceutics and other bioactive components [7-10].

In our ongoing pharmacological screening program on biodiversity of fungi present in Indian landscape using high throughput screening (HTS), we have identified a notable antiproliferative activity against cancer cells in extracts/fractions of a fungus Bipolaris papendorfii, coded as PM0853873 isolated from the rice fields of Dera, Himachal Pradesh, India. Hamigerone was originally reported as the major secondary metabolite of Hamigera avellanea but no pharmacological activity was reported [11]; similarly radicinol was isolated from Cochliobolus lunata but no pharmacological activity was reported [12]. Apoptosis is essential in the homeostasis of normal tissues of the body. The two important genes involved in this process are the BCL-2 gene and p53 gene. BCL-2 is a gene of antiapoptosis and is crucial in preventing apoptosis whereas p53 gene is known as tumor suppressor gene. Cellular stresses, particularly DNA damage, are sensed by proteins such as ATM and DNA-PK, which phosphorylate and stabilize p53 which in turn cause apoptosis to the cancer cells [13]. The apoptotic pathway is related to induction of p53 and this pathway is held in check by the antiapoptotic gene BCL-2 [14]. The protooncogene BAX forms a heterodimer with BCL-2 and accelerates the process of apoptosis. We describe here the identification and bioactivity of the lead compounds hamigerone and radicinol from this culture. In this study, we also demonstrate for the first time the novel in vitro antiproliferative properties 


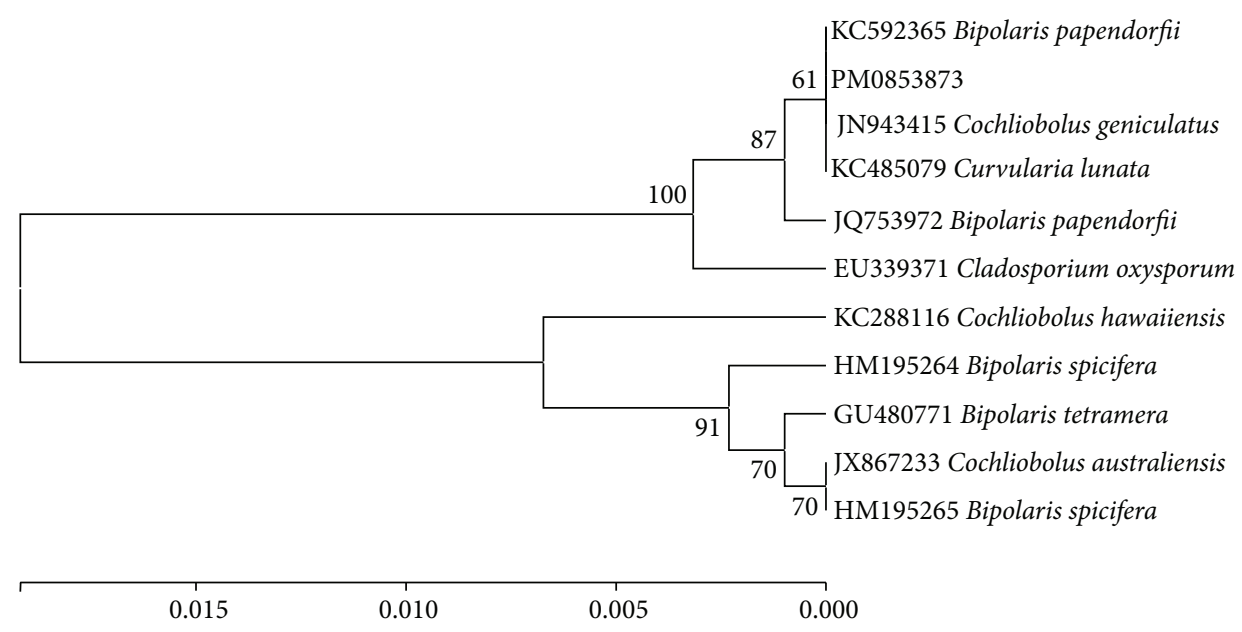

FIGURE 1: Phylogenetic analysis of the ITS region sequence obtained from sample PM0853873 in comparison with the nearest type strain sequences. The tree was constructed based on rRNA gene sequences (ITS region) using the Maximum Composite Likelihood Method.

of hamigerone and radicinol in cancer cells. Both the compounds are inducing apoptosis in Panc-1 cancer cells by favorably modulating p53, BCL-2, and caspase 3 expression.

\section{Materials and Methods}

2.1. General. HPLC was performed in Lichrosphere RP-18, $125 \times 4 \mathrm{~mm}$ column using Shimadzu LC-2010 CHT Liquid Chromatography. Water preparative HPLC was used for final purification. Solvents used were of HPLC grade and normal column chromatography (CC) was performed with distilled commercial-grade solvents. Silica gel $\left(\mathrm{SiO}_{2}, 200-300\right.$ mesh) was used for CC and $\mathrm{GF}_{254}(30-40 \mathrm{~mm})$. TLCs were procured from Merck. NMR spectra in $\mathrm{CDCl}_{3}$ were recorded on Bruker $300 \mathrm{MHz}$ spectrometer with TMS as the internal standard with chemical shift $\delta$ values in ppm and coupling constant J in Hz. ESI LC-MS was from Bruker Daltonics. Flash chromatography was performed on CombiFlash Sq 16X Teledyne Technologies Company ISCO attached with UV/VIS detector, (RediSep Flash Column silica 12 g, CHCl3/ $\mathrm{MeOH}$ gradient system). Final purification was achieved by preparative HPLC using RP-18 column $(10 \times 25 \mathrm{~mm}, 10 \mu)$ and acetonitrile/water as a solvent system.

2.2. Cell Culture Reagents. All the cell lines were obtained from ATTC, USA. McCoy's 5a medium, MEM, RPMI1640, FBS, BSA, isopropanol, dimethylsulfoxide (DMSO), formaldehyde, 3-(4,5-dimethylthiazol-2-yl)-2,5-diphenyl tetrazolium bromide, Triton X-100, and PBS were obtained from Sigma, USA. Hoechst 3342 and Dylight 549 were obtained from Thermo Fisher Scientific, USA. All the antibodies, namely, BCL-2 (SC-738), p53 (SC-126), and cleaved caspase 3 (SC-22171), were procured from Santa Cruz Biotechnology, Inc., USA.

2.3. Isolation and Identification of Fungus. The strain PM0853873 was isolated from the soil samples collected from Dera rice field during October 2007. The culture was isolated using soil plate method [15] using potato carrot agar (Hi Media) supplemented with $50 \mathrm{mg} / \mathrm{L}$ of chloramphenicol and maintained on potato dextrose agar (Hi Media) supplemented with $50 \mathrm{mg} / \mathrm{L}$ of chloramphenicol for identification and fermentation. The strain was identified as Bipolaris papendorfii by partial sequence analysis of the internal transcribed spacer region (ITS) using ITS1 and ITS4 primers [16]. A nucleotide to nucleotide BLAST [17] query of the gene bank database (http://www.ncbi.nlm.nih.gov/BLAST) recovered KC592365 Bipolaris papendorfii (92\%) as the closest match to the ITS rDNA of PM0853873 (100.0\%). Evolutionary analyses (Figure 1) were performed using MEGA6 [18].

2.4. Large-Scale Production of the Fungus. A loop full of the well grown culture from slant maintained on potato dextrose agar (PDA) was transferred to a $500 \mathrm{~mL}$ conical flask with $100 \mathrm{~mL}$ liquid medium containing soluble starch $1.5 \mathrm{~g}$; soya bean meal $1.5 \mathrm{~g}$; yeast extract $0.2 \mathrm{~g}$; corn steep liquor $0.1 \mathrm{~g}$; glucose $0.5 \mathrm{~g}$; $\mathrm{CaCO}_{3} 0.2 \mathrm{~g} ; \mathrm{NaCl} 0.5 \mathrm{~g}$; glycerol $1.0 \mathrm{~g}$ in demineralized water at $\mathrm{pH}$ 5.5. This was grown on rotary shaker at $220 \mathrm{rpm}$ for $72 \mathrm{~h}$ at $28^{\circ} \mathrm{C}$ and was used as seed medium. Potato dextrose broth medium (Hi Media) was used for production. The $\mathrm{pH}$ of the medium was adjusted to 6.5 prior to sterilization. Twenty-five, $1000 \mathrm{~mL}$ flasks containing $200 \mathrm{~mL}$ of the above medium were inoculated with $1 \%$ of the seed culture and incubated on rotary shaker at $220 \mathrm{rpm}$ for $72 \mathrm{~h}$ at $28^{\circ} \mathrm{C}$.

2.5. Purification of Compounds. $5 \mathrm{~L}$ fermentation broth was filtered through Whatman number 1 filter paper to separate biomass. Methanol was added to the biomass, stirred for $40 \mathrm{~min}$, and filtered. The filtrate was evaporated on rotary evaporator to remove methanol and aqueous residue was partitioned with ethyl acetate; the organic layer was concentrated on rotary evaporator to remove solvent, which yielded 
<smiles>CC(=O)CC1=C(C)C=C2CC(C)C(=O)C(C)C2C1/C=C(\C)C1OC1(C)/C=C/C(=O)O</smiles>

Compound 1<smiles>C/C=C/c1cc2c(c(=O)o1)C(O)C(O)C(C)O2</smiles>

Compound 2

FIGURE 2: Structures of hamigerone (1) and radicinol (2).

$500 \mathrm{mg}$ crude extract. The crude extract was subjected to flash chromatography $16 \mathrm{X}$ on ISCO Combiflash system using RediSep silica column $\left(\mathrm{SiO}_{2}, 200-300\right.$ mesh, 12 g; petroleum ether/ethyl acetate gradient). Semipure compounds $\mathbf{1}$ and $\mathbf{2}$ were obtained from the fractions eluted with $10 \%$ ethyl acetate in petroleum ether. Final purification of compound $\mathbf{1}$ and $\mathbf{2}$ was performed on preparative HPLC (Waters PrepLC 4000 system, RP-18 column $8 \times 250 \mathrm{~mm}$ (Lichrosphere), $10 \mu$; 2$100 \%$ acetonitrile in $30 \mathrm{~min}$ gradient against water, $5 \mathrm{~mL} / \mathrm{min}$ flow). The peak at RT 28.2 was collected and evaporated the solvent to get $8 \mathrm{mg}$ pure compound 1 . In a similar preparative HPLC experiment semipure compound 2 appeared at $16 \mathrm{~min}$ to give $12 \mathrm{mg}$ pure compound. The purity of the compounds were determined by Analytical HPLC.

2.6. Identification of the Substances. These compounds were characterized by spectroscopic data (UV, ${ }^{1} \mathrm{H}-\mathrm{NMR},{ }^{13} \mathrm{C}$ NMR, and LC-MS). Compounds $\mathbf{1}$ and $\mathbf{2}$ were identified as hamigerone and radicinol respectively. LC MS data indicated the molecular weight of compound $\mathbf{1}$ as 412 and compound 2 as 238 .

\section{Screening for Anticancer Activity}

3.1. Cell Proliferation Assay. Cell growth was measured by $3-$ (4,5-dimethylthiazol-2-yl)-2,5-diphenyl tetrazolium bromide (MTT) method [19]. Cells were seeded at the appropriate concentrations to prevent confluence throughout the experiment. After $24 \mathrm{~h}$ of incubation, cells were treated with serial concentrations of the compounds. Control cells were treated with equal concentration of DMSO (never exceeding $0.1 \%$ ). At $72 \mathrm{~h}$ after treatment, aliquots of $10 \mu \mathrm{L}$ of MTT $(5 \mathrm{mg} / \mathrm{mL})$ were added to each well and incubated for $4 \mathrm{~h}$ at $37^{\circ} \mathrm{C}$. The supernatant was removed and $100 \mu \mathrm{L}$ of isopropanol was added. The color intensity of reduced MTT was measured using Tecan Sapphire multifluorescence microplate reader (Tecan, Germany, GmbH) at $595 \mathrm{~nm}$. DMSO-treated cells were considered untreated control and assigned a value of $100 \%$.

3.2. In Vitro Protein Expression (by High Content Screening). Panc-1 cells were seeded in 96-well plates at a density of $1 \times 10^{4}$ cells/well. $24 \mathrm{~h}$ after seeding, medium was replaced with fresh medium. Panc- 1 cells were treated with $1.9 \mu \mathrm{M}$ of hamigerone and $10.50 \mu \mathrm{M}$ of radicinol for $12 \mathrm{~h}$. At the end of every time point, to determine the protein expression, the cells were fixed with $3.7 \%$ formaldehyde in PBS for 10 minutes at room temperature, followed by permeabilization with $0.15 \%$ Triton X-100 for 10 minutes. After permeabilization, the cells were blocked with 5\% BSA for $2 \mathrm{~h}$. After blocking step specific primary antibody was added for $1 \mathrm{~h}$. Following primary antibody incubation, the nucleus was stained with Hoechst 3342 (blue) and primary antibodies of different protein (BCL-2, p53, and caspase 3) were localized by secondary antibody labeled with Dylight 549 (red). Immunofluorescence of BCL-2, p53, and cleaved caspase 3 was determined by scanning the plates on Cellomics Array Scan VTI HCS Reader with 20X magnification (Thermo Fisher Scientific Inc., Waltham, MA).

All the data points were analyzed using the target activation and molecular translocation bioalgorithm of Cellomics and the quantitative data was expressed as percentage (\%) activation in comparison to the DMSO control cells. 1000 cells were counted for each replicate well and the results were presented as an average \pm SE. Bioapplication enables identification of the cell and cytoplasmic areas; the blue traces define the cell boundaries, while the orange traces cells rejected from the analysis. The scoring outputs used were total cellular/nuclear intensity and redistribution of fluorescence intensity from the nucleus to the cytoplasm (entropy intensity change) [20,21].

3.3. Statistical Analysis. The data shown are the mean values of at least three replicate experiments and expressed as means \pm SD. Differences between groups were analyzed using two sided $t$-test and ANOVA with $P<0.05$ considered statistically significant. In cases in which averages were normalized to controls, the SDs of each nominator and denominator were taken into account in calculating the final SD. Statistical analyses were conducted using GraphPad Prism software 3.03 package (GraphPad Software, Inc., CA, USA).

\section{Results and Discussion}

4.1. Isolation and Structural Elucidation. The bioactivity guided purification of the crude extract obtained from the fermented whole broth yielded pure bioactive compounds 1 (hamigerone) and $\mathbf{2}$ (radicinol) (Figure 2). These compounds 
TABLE 1: $\mathrm{IC}_{50}$ of hamigerone and radicinol in different cell lines.

\begin{tabular}{|c|c|c|c|c|}
\hline \multirow{2}{*}{ Cell line } & \multicolumn{4}{|c|}{$\mathrm{IC}_{50}$ in $\mu \mathrm{M}( \pm \mathrm{SD})$} \\
\hline & Hamigerone & Radicinol & Gemcitabine & Flavopiridol \\
\hline Panc-1 (pancreatic) & $1.9 \pm 0.92$ & $10.50 \pm 1.4$ & $0.38 \pm 0.04$ & $0.62 \pm 0.05$ \\
\hline ACHN (renal) & $4.3 \pm 0.78$ & $14.28 \pm 1.8$ & $0.78 \pm 0.07$ & $0.91 \pm 0.11$ \\
\hline Calul (lung) & $2.91 \pm 1.1$ & $12.60 \pm 0.87$ & $0.98 \pm 0.11$ & $0.79 \pm 0.19$ \\
\hline H460 (non-small cell lung) & $2.42 \pm 0.63$ & $21.6 \pm 3.2$ & $1.23 \pm 0.23$ & $0.82 \pm 0.09$ \\
\hline HCT116 (colon) & $2.91 \pm 0.87$ & $25 \pm 2.9$ & $1.15 \pm 0.21$ & $0.73 \pm 0.08$ \\
\hline MCF10A (normal breast epithelium) & $>30$ & $>30$ & $>10$ & $>10$ \\
\hline
\end{tabular}

$\mathrm{IC}_{50}$ values of hamigerone and radicinol in different cancer cells at $48 \mathrm{~h}$. The cells were exposed to different concentrations at end of $48 \mathrm{~h}$; cytotoxicity was measured using live cell dehydrogenase assay.

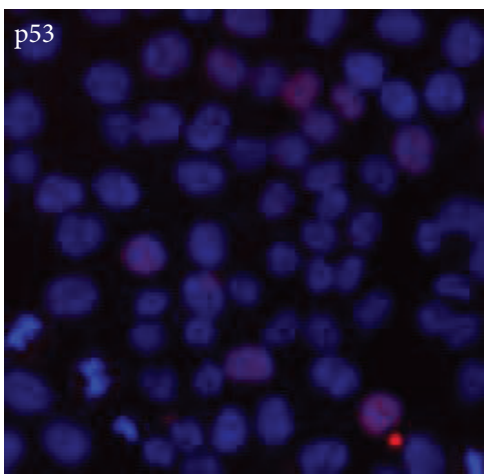

Control

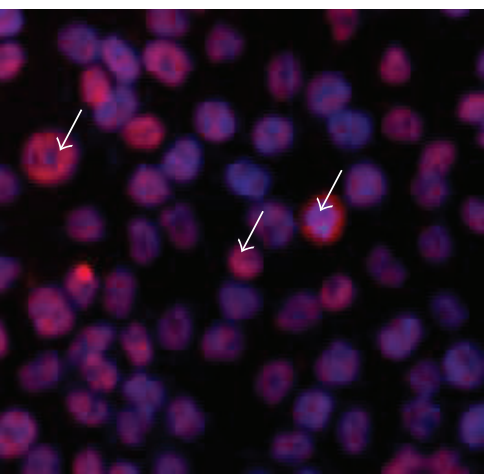

Hamigerone

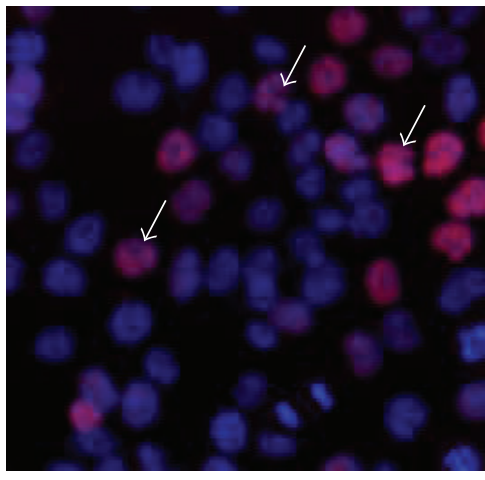

Radicinol

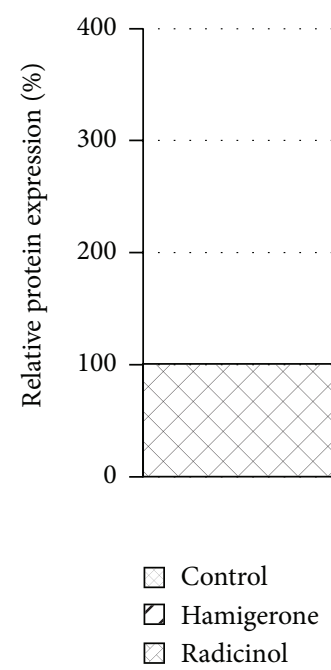

FIGURE 3: Elevation of p53 expression on treatment with hamigerone and radicinol in Panc-1 cells. The nucleus was stained with Hoechst 3342 (blue color), the expression of p53 protein levels was detected using Dylight 549 (red color), and the represented images are composite images of both channels. The quantitative data of p53 expression against untreated control cells is denoted as bar diagram. 1000 cells were counted for each replicate well and the results were presented as an average \pm SE.

were characterized by spectroscopic data $\left(\mathrm{UV},{ }^{1} \mathrm{H}-\mathrm{NMR},{ }^{13} \mathrm{C}-\right.$ $\mathrm{NMR}$, and LC-MS). All the values were in complete accord with that of the reported values $[11,12,22]$.

Hamigerone was previously isolated from the fungus Hamigera avellanea and exhibits in vitro growth inhibitory activity against phytopathogenic fungi [11].

Radicinol, the phytotoxic compound, was produced on carrot disks by Cochliobolus lunata IFO 6288 [12]. It was also produced by Bipolaris coicis, Alternaria radicina, and $A$. chrysanthemi [22-24].

4.2. Antiproliferative Effect and In Vitro Protein Expression of Hamigerone and Radicinol. Hamigerone induced cytotoxicity in various cancer cell lines with an $\mathrm{IC}_{50}$ ranging from $1.9 \mu \mathrm{M}$ to $4.3 \mu \mathrm{M}$. Similarly radicinol showed lesser 


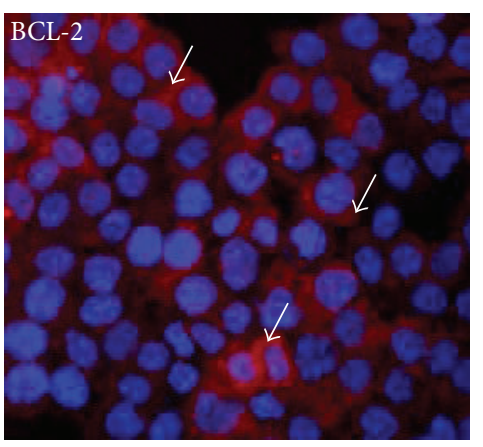

Control

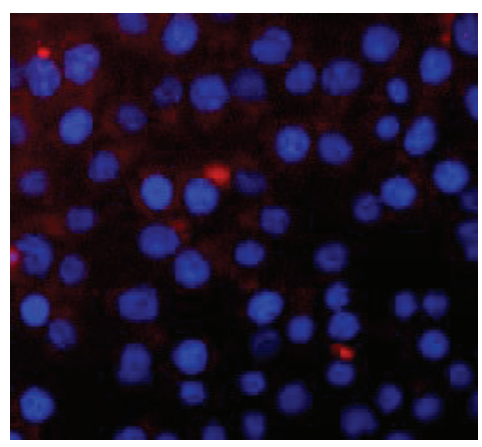

Hamigerone

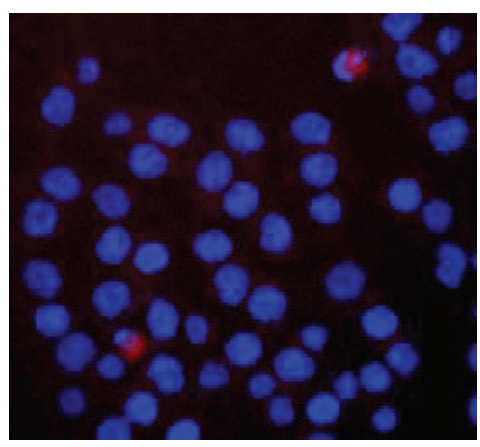

Radicinol

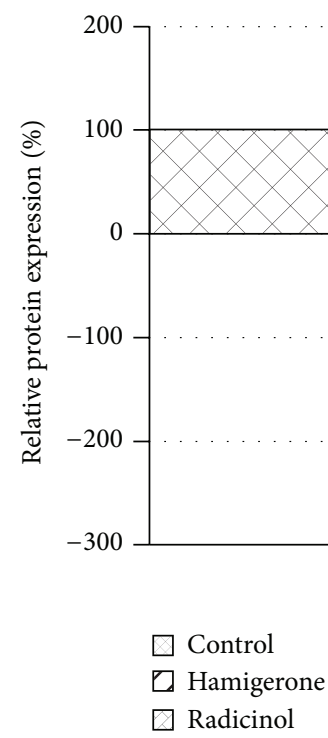

FIGURE 4: Decreased expression of BCL-2 levels on treatment with hamigerone and radicinol in Panc-1 cells. The nucleus was stained with Hoechst 3342 (blue color), the expression of BCL-2 protein levels was detected using Dylight 549 (red color), and the represented images are composite images of both channels. The quantitative data of BCL-2 expression against untreated control cells is represented as bar diagram. 1000 cells were counted for each replicate well and the results were presented as an average \pm SE.

efficacy as a poor inducer of cytotoxicity towards the cancer cell lines with an $\mathrm{IC}_{50}$ in the range of $10.50 \mu \mathrm{M}-$ $25 \mu \mathrm{M}$ (Table 1). Both the compounds were not toxic to normal breast epithelial cell line (MCF10A), as there was no growth inhibition up to a concentration of $30 \mu \mathrm{M}$. These findings suggest that these compounds are specific towards the abnormally proliferating cells [25] wherein hamigerone showed better toxicity to cancer cells as compared to radicinol. Based on the potent antiproliferation activity of both hamigerone and radicinol in Panc-1 cells, these compounds were further profiled for p53, BCL-2, and caspase 3 activity using high content screening tool Cellomics VTI Array Scan.

The p53 protein is known as a cellular gate-keeper. In general, in more than $70 \%$ of the tumors p53 status is either mutated or deleted. Activating p53 in cancer cells aids in driving the cancer cells into apoptosis. We have analyzed p53 protein expression in Panc- 1 cells after $12 \mathrm{~h}$ of treatment with hamigerone and radicinol. The results showed 3.5-fold and 2.4- fold increased expression of p53 in Panc-1 cells (Figure 3), respectively. The quantitative expression level of this protein is represented as bar diagram.

It was also observed that hamigerone showed more significant induction of p53 (red color Ch2) when compared with radicinol. The significance of p53 in cell cycle arrest was also noted with Selaginella tamariscina extract in human ovarian cancer cell line A-2780 [26].

BCL-2 is an antiapoptotic protein. On treatment with hamigerone we noted 2.5-fold decreased expression of BCL2 as compared with untreated control cells (Figure 4), while radicinol showed marginal reduction (1-fold). This data reveals that hamigerone was more potent than radicinol in reducing BCL-2 expression in Panc-1 cells. The bar diagram indicates the quantitative expression of BCL-2 protein levels. In another study resveratrol, a phytoalexin present in grapes and other food products, induces apoptosis in cancer cells by decreasing BCL-2 expression in HL60 cells and gives rise to proteolytic cleavage of caspase substrate PARP [27] thereby causing apoptosis to the cancer cells. 


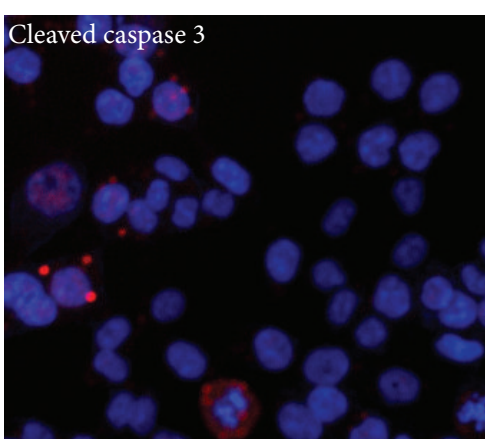

Control

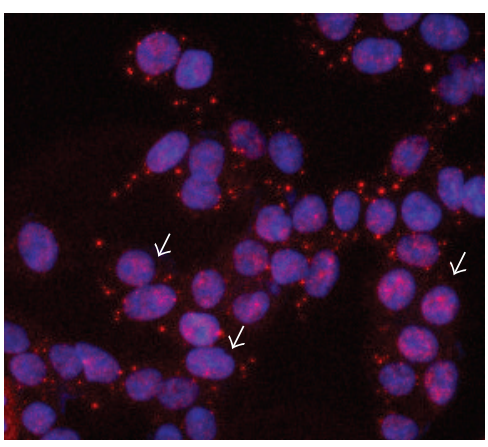

Hamigerone

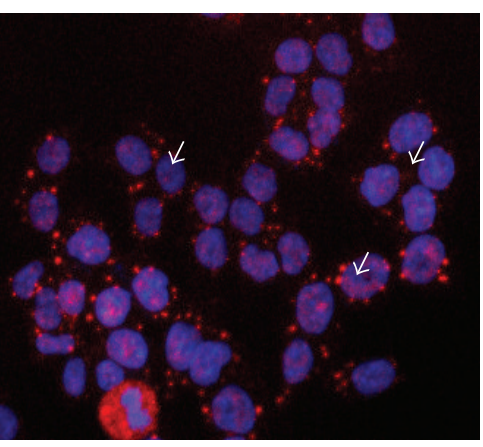

Radicinol

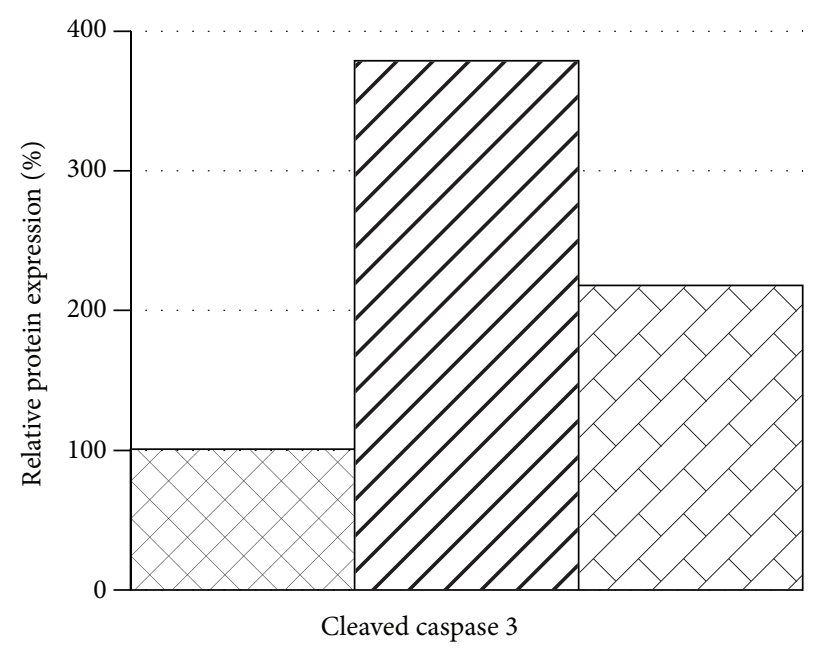

Control

$\square$ Hamigerone

Radicinol

FIGURE 5: Induction of caspase 3 expression on treatment with hamigerone and radicinol in Panc-1 cells. The nucleus was stained with Hoechst 3342 (blue color), the expression of caspase 3 protein levels was detected using Dylight 549 (red color), and the represented images are composite images of both channels. The quantitative data of caspase 3 expression against control is showed as bar diagram. 1000 cells were counted for each replicate well and the results were presented as an average \pm SE.

Furthermore we evaluated the cleaved caspase 3 activity in the cells treated with these compounds. In Panc-1 cells cleaved caspase 3 levels were higher (3.9-fold and 2.1-fold) in cells treated with hamigerone and radicinol as compared to untreated cells, respectively (Figure 5). These findings suggest the cytotoxicity effect of hamigerone and radicinol in cancer cells could be via induction of caspase 3 activation. The quantitative expression level of this protein against untreated controls is represented as bar diagram.

Of all the proteins involved in the activation and execution of apoptosis, the caspase 3 stands out as being crucial for this process [28].

In this study we have identified that hamigerone and radicinol interact with multiple cancer targets whose implication in cancer drug discovery is well described previously. Based on our findings, these molecules can become a potential startup point for developing new scaffold which can modulate potential cancer targets.

\section{Conflict of Interests}

The authors declare that there is no conflict of interests regarding the publication of this paper.

\section{Acknowledgment}

We are thankful to the analytical discovery group at Piramal Enterprises Limited for recording spectral data.

\section{References}

[1] D. J. Newman and G. M. Cragg, "Natural products as sources of new drugs over the last 25 years," Journal of Natural Products, vol. 70, no. 3, pp. 461-477, 2007.

[2] J. C. Frisvad, U. Thrane, and O. Filtenborg, "Role and use of metabolites in fungal taxonomy," in Chemical Fungal Taxonomy, J. C. Frisvad, P. D. Bridge, and D. K. Arora, Eds., pp. 289-319, Marcel Dekker, New York, NY, USA, 1998. 
[3] A. A. L. Gunatilaka, "Natural products from plant-associated microorganisms: distribution, structural diversity, bioactivity, and implications of their occurrence," Journal of Natural Products, vol. 69, no. 3, pp. 509-526, 2006.

[4] S. G. Bernier, D. D. Lazarus, E. Clark et al., "A methionine aminopeptidase-2 inhibitor, PPI-2458, for the treatment of rheumatoid arthritis," Proceedings of the National Academy of Sciences of the United States of America, vol. 101, no. 29, pp. 10768-10773, 2004.

[5] J. Wang, T. Wiltshire, Y. Wang et al., "ATM-dependent CHK2 activation induced by anticancer agent, irofulven," The Journal of Biological Chemistry, vol. 279, no. 38, pp. 39584-39592, 2004.

[6] Y. W. Chin, M. J. Balunas, H. B. Chai, and A. D. Kinghorn, "Drug discovery from natural sources," AAPS Journal, vol. 8, no. 2, pp. E239-E253, 2006.

[7] A. L. Harvey, "Natural products in drug discovery," Drug Discovery Today, vol. 13, no. 19-20, pp. 894-901, 2008.

[8] G. R. Eldridge, H. C. Vervoort, C. M. Lee et al., "Highthroughput method for the production and analysis of large natural product libraries for drug discovery," Analytical Chemistry, vol. 74, no. 16, pp. 3963-3971, 2002.

[9] S. K. Deshmukh, P. D. Mishra, A. Kulkarni-Almeida et al., "Antiinflammatory and anticancer activity of ergoflavin isolated from an endophytic fungus," Chemistry and Biodiversity, vol. 6, no. 5, pp. 784-789, 2009.

[10] P. Giridharan, S. A. Verekar, A. Khanna, P. D. Mishra, and S. K. Deshmukh, "Anticancer activity of sclerotiorin, isolated from an endophytic fungus Cephalotheca faveolata Yaguchi, Nishim. \& Udagawa," Indian Journal of Experimental Biology, vol. 50, no. 7, pp. 464-468, 2012.

[11] J. Breinholt, A. Kjœr, C. E. Olsen, B. R. Rassing, and C. N. Rosendahl, "Hamigerone and dihydrohamigerone: two acetatederived, antifungal metabolites from Hamigera avellanea," Acta Chemica Scandinavica, vol. 51, no. 12, pp. 1241-1244, 1997.

[12] N. Manabu and M. Shingo, "Radicinol, a new metabolite of Cochliobolus lunata, and absolute stereochemistry of radicinin," Tetrahedron Letters, vol. 18, no. 37, pp. 3271-3272, 1977.

[13] R. J. Bold, P. M. Termuhlen, and D. J. McConkey, "Apoptosis, cancer and cancer therapy," Surgical Oncology, vol. 6, no. 3, pp. 133-142, 1997.

[14] G. C. Shore and J. Viallet, "Modulating the bcl-2 family of apoptosis suppressors for potential therapeutic benefit in cancer," The American Society of Hematology, vol. 1, pp. 226-230, 2005.

[15] J. H. Warcup, "The soil-plate method for isolation of fungi from soil," Nature, vol. 166, no. 4211, pp. 117-118, 1950.

[16] T. J. White, T. Bruns, S. Lee, and J. Taylor, "Amplification and direct sequencing of fungal ribosomal RNA genes for phylogenetics," in PCR Protocols: A Guide to Methods and Applications, M. A. Innis, D. H. Gelfand, J. J. Sninsky, and T. J. White, Eds., pp. 315-322, Academic Press, San Diego, Calif, USA, 1990.

[17] S. F. Altschul, W. Gish, W. Miller, E. W. Myers, and D. J. Lipman, "Basic local alignment search tool," Journal of Molecular Biology, vol. 215, no. 3, pp. 403-410, 1990.

[18] K. Tamura, G. Stecher, D. Peterson, A. Filipski, and S. Kumar, "MEGA6: molecular evolutionary genetics analysis version 6.0," Molecular Biology and Evolution, vol. 30, pp. 2725-2729, 2013.

[19] T. Mosmann, "Rapid colorimetric assay for cellular growth and survival: application to proliferation and cytotoxicity assays," Journal of Immunological Methods, vol. 65, no. 1-2, pp. 55-63, 1983.
[20] J. Low, L. Stancato, J. Lee, and J. J. Sutherland, "Prioritizing hits from phenotypic high-content screens," Current Opinion in Drug Discovery and Development, vol. 11, no. 3, pp. 338-345, 2008.

[21] G. J. F. Ding, P. A. Fischer, R. C. Boltz et al., "Characterization and quantitation of NF- $\kappa \mathrm{B}$ nuclear translocation induced by interleukin-1 and tumor necrosis factor- $\alpha$," The Journal of Biological Chemistry, vol. 273, no. 44, pp. 28897-28905, 1998.

[22] H. Nakajima, T. Ishida, Y. Otsuka, T. Hamasaki, and M. Ichinoe, "Phytotoxins and related metabolites produced by Bipolaris coicis, the pathogen of job's tears," Phytochemistry, vol. 45, no. 1, pp. 41-45, 1997.

[23] M. Solfrizzo, C. Vitti, A. de Girolamo, A. Visconti, A. Logrieco, and F. P. Fanizzi, "Radicinols and radicinin phytotoxins produced by Alternaria radicina on carrots," Journal of Agricultural and Food Chemistry, vol. 52, no. 11, pp. 3655-3660, 2004.

[24] H. Sheridan and A. Canning, "Novel radicinol derivatives from long-term cultures of Alternaria chrysanthemi," Journal of Natural Products, vol. 62, no. 11, pp. 1568-1569, 1999.

[25] R. Yang, H. Hanwell, J. Zhang, R. Tsao, and K. A. Meckling, "Antiproliferative activity of pomiferin in normal (MCF-10A) and transformed (MCF-7) breast epithelial cells," Journal of Agricultural and Food Chemistry, vol. 59, no. 24, pp. 1332813336, 2011.

[26] I. Lee, A. Nishikawa, F. Furukawa, K. Kasahara, and S. Kim, "Effects of Selaginella tamariscina on in vitro tumor cell growth, p53 expression, G1 arrest and in vivo gastric cell proliferation," Cancer Letters, vol. 144, no. 1, pp. 93-99, 1999.

[27] Y. J. Surh, Y. J. Hurh, J. Y. Kang, E. Lee, G. Kong, and S. J. Lee, "Resveratrol, an antioxidant present in red wine, induces apoptosis in human promyelocytic leukemia (HL-60) cells," Cancer Letters, vol. 140, no. 1, pp. 1-10, 1999.

[28] D. W. Nicholson and N. A. Thornberry, "Caspases: killer proteases," Trends in Biochemical Sciences, vol. 22, no. 8, pp. 299306, 1997. 

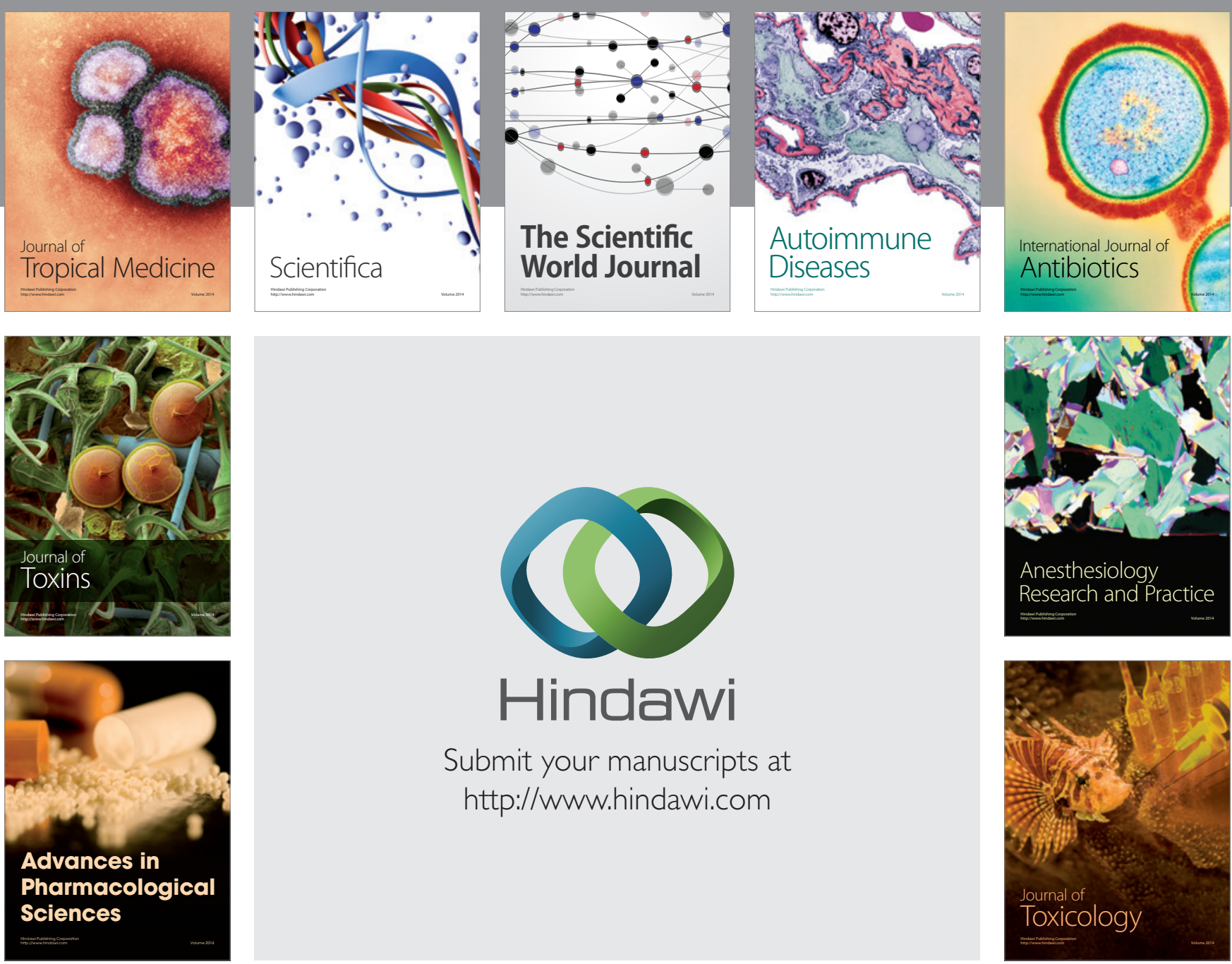

\section{Hindawi}

Submit your manuscripts at

http://www.hindawi.com
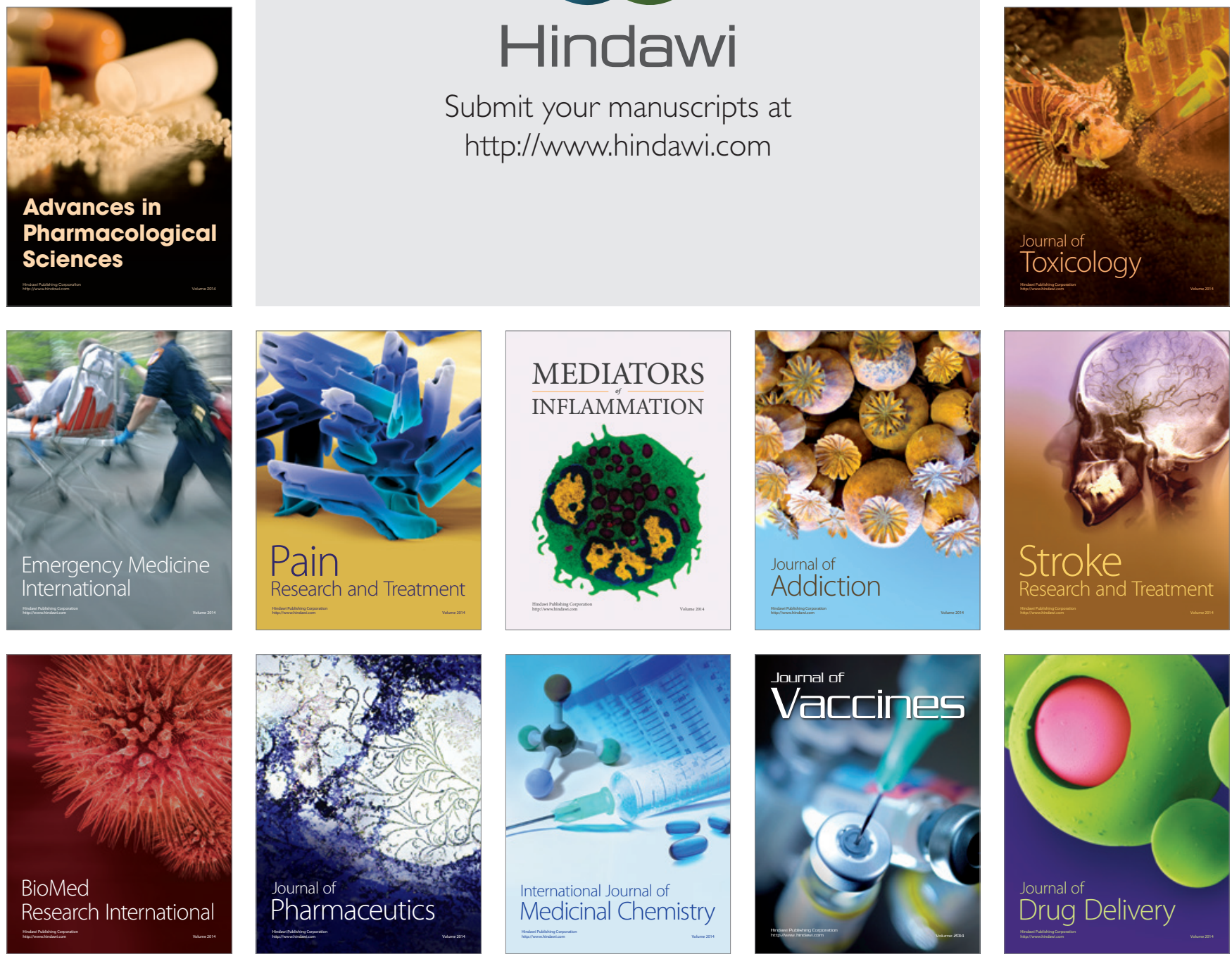